\title{
Correction to: Religiosity and Health-Related Quality of Life: A Cross-Sectional Study on Filipino Christian Hemodialysis Patients
}

\author{
Jonas Preposi Cruz ${ }^{1} \cdot$ Paolo C. Colet $^{1} \cdot$ Hikmet Qubeilat $^{1}$ • \\ Jazi Al-Otaibi ${ }^{1} \cdot$ Erwin I. Coronel $^{2} \cdot$ Roderick C. Suminta $^{1}$
}

Published online: 28 May 2018

(C) Springer Science+Business Media, LLC, part of Springer Nature 2018

\section{Correction to: J Relig Health (2016) 55:895-908 \\ https://doi.org/10.1007/s10943-015-0103-9}

The authors regret that the following error occurred in the original publication of the article. The corrected text has been presented with this erratum.

In the Ethical Consideration section, the first statement, "The hospital's research ethics committee granted permission to conduct the study" should read "The hospital's administration granted permission to conduct the study."

The original article can be found online at https://doi.org/10.1007/s10943-015-0103-9.

Jonas Preposi Cruz

cruzjprn@gmail.com

1 College of Applied Medical Sciences, Shaqra University, PO Box 1678, Dawadmi 11911, Saudi Arabia

2 Central Security Hospital, Riyadh, Saudi Arabia 